\title{
JOKES IN IRAN
}

\author{
Bakhtiar Naghdipour
}

\begin{abstract}
This study touches upon the main targets and functions of jokes in Iran. To this end, a corpus of 1000 Persian jokes was randomly selected from different online websites and classified based on their targets. A survey was also administered to 200 university students from around the country to investigate their opinions on the characteristics and functions, or what these jokes may reflect or perpetuate in the Iranian society. The analysis of the collected data revealed that the targets of Persian jokes are mostly ethnic and political issues, which violate the social and political taboos and censorship to achieve their end. The prevalence of ethnic jokes could highlight the unsettling relationship and competition between ethnic groups and the established majority for better socioeconomic and socio-political opportunities in this multi-ethnic and multilingual society. This study concludes with a call for further interdisciplinary research into the various factors and forces that may influence the dynamics of jokes in this context.
\end{abstract}

Keywords: ethnic jokes, humor, Iran, Persian jokes, political jokes, sexist jokes

\section{INTRODUCTION}

Jokes are ubiquitous, and they reach their national and international audience through the Internet, mobile phones, friends, colleagues, and other channels or means of communication. Thousands of individuals and hundreds of blogs and websites are involved in the constant spreading of joking, stereotyping, and making myths about different ethnic and religious groups, races, genders, and even animals. In Iran, jokes are so widespread that they are even heard at official meetings, gatherings, and news conferences. Religious figures also exploit jokes in their sermons to consolidate their reasoning and convince people of the veracity of their complicated arguments or narratives. Despite their popularity, however, there is scarcity of research on different functions of jokes in this context, perhaps because of the interdisciplinary nature of studying the humor phenomena that require collaborative work among a team of scholars, as well as transdisciplinary skills and methods.

Different opinions about whether jokes depict any reality in society or joke makers and tellers have any hidden agenda behind their involvement in 
joking practices have been voiced. The debate epitomizes best the old riddle of a relationship between language and reality, or language and culture. On the one hand, the Sapir-Whorf hypothesis considers language as the shaping agent of different cultural and social processes (cited in Pérez-Arce 1999), seeing culture at the mercy of language. On the other hand, Davies (2007) assumes that political and ethnic jokes rarely affect the joke tellers and hearers as far as the cultural and social changes are concerned, underestimating the prowess of language against the hegemony of cultural and social structures. While recognizing the likely contributions of these two extremes to the studies of the interface between cultural and linguistic phenomena, proposing an alternative in support of reciprocal and bi-directional relationship between language and culture seems inevitable. Simply put, even though it is less likely to argue that jokes, for instance, have stirred the Arab Spring movement, it is then less convincing to admit that language is shaped by cultural and social agendas, leaving no impact on them. All things being equal, language, either intentionally or incidentally, possesses the leverage to emancipate, entertain, criticize, include, or otherwise ostracize people in different situations and under different circumstances. Prior to reviewing the theoretical and practical perspectives on jokes, the following section gives a brief account of the social fabric and dynamics of today's Iranian society.

Iran consists of 28 provinces where various ethnic groups live side-by-side using languages such as Persian, Turkish, Kurdish, Lurish, Baluchi, Armenian, and Arabic. Being associated with specific sociolinguistic and geographical markers, some of these languages are at times unintelligible to the speakers of standard Persian. In addition to enriching its cultural heritage, this linguistic diversity, which oftentimes corresponds to a spectrum of ethnic diversity, has become a distinctive determiner when it comes to joking practices across the country. The socio-economic rivalry among social strata in more populated urban areas could be another reason for the birth of jokes, in particular, ethnic jokes. These places have been the battleground of ethnic challenges and conflicts, especially after the 1970s. Before the Islamic revolution in 1979, a majority of people in small towns and rural areas were leading a feudalistic system of life, keeping their farms or herding their livestock. Meeting the demands of this self-sufficient lifestyle did not leave them any room for abrupt socio-economic changes or developments. After the revolution, however, feudalism, whose pillars had started to shake some two decades before, collapsed, and many people moved to big towns and cities in search for better living standards, job opportunities, and education. The new lifestyle exerted a huge pressure on these immigrants to assimilate into new linguistic and social groups. Their reluctance to an easy and quick conformity to the mainstream social norms and 
their rivalry with the established majority for the better social and economic well-being turned more obstinate minorities into the targets of ethnic jokes.

During this time, the post-revolutionary theocratic system undertook major reforms in different cultural, social, educational, and political arenas by institutionalizing and indoctrinating the Islamic norms and values throughout the country. This system has showed almost a zero tolerance policy to the voices of its critics or opponents. Political jokes, which have poured out as a reaction to both visible and invisible social, political, and ideological crackdown, have predominantly targeted a lack of freedom in society, as well as the inefficiency of politicians in the face of national and international challenges. Recently, some columnists and political figures have publicly criticized the jokes that poke fun at old senior clerics who are still active on the political scene. For example, Taraghi (2012), an advisor to the Supreme Leader, condemned telling jokes about Tehran Friday Prayer Imam as unfair and belittling to his achievements and contributions to the Islamic community.

The following section draws on several theories that account for different roles of humor. In particular, it gives an overview of the social, psychological, and political functions of jokes as an important means of delving into the sociocultural and socio-political underpinnings of any given social context. In the light of these theories, this study intends to provide a classification of Persian jokes based on their targets. It also aims to offer an insider perspective into the characteristics and functions of different types of jokes in this context.

\section{REVIEW OF LITERATURE}

The debate on the nature and role of humor dates back to the thinkers such as Plato and Aristotle (Provine 2000), Kant (LaFollette \& Shanks 1993), and Schopenhauer (Provine 2000), just to name a few. The ancient literature also abounds in examples of people's use of humor to express their attitudes towards each other or different social issues (Bullough \& Bullough 1994; Holt 2008). However, this debate is still ongoing, as new theories are emerging to cater for the new challenges and new players on the social scene in different contexts. In his linguistic-semantic theory of verbal humor, Raskin (1985 [1944]) classified humor theories into cognitive, or theories of incongruity and contrast; social or theories of hostility, aggression, superiority, triumph, derision and disparagement; and psychoanalytical or release theories. From another perspective, Attardo (1994) categorized humor into two semantic and pragmatic facets: the semantic dimension views humor as a depiction of incongruity, whereas the pragmatic dimension considers humor as a violation of Grice's 
Cooperative Principle. With regard to its role in society, humor may function as a social corrective, which is used by society to correct the deviant behavior (Bergson 2004 [1911]), or as a defense mechanism to neutralize aggressive or violent behavior (Oshima 2000). Notwithstanding the diversity of theories on its type and function, however, humor still lacks a comprehensive theory. Veatch (1998) attributed the absence of a unified theory to the interdisciplinary nature of studying humor, and to the fact that various factors could influence the individuals' use and interpretation of humor in different situations.

Among different genres of humor, jokes are predominantly narrative and contain a story of, for instance, stupidity, leaving a less complicated cognitive load on individuals to narrate or make sense of them. Jokes address an array of issues, ranging from the most ideological beliefs to the daily affairs of a community or nation. Ethnic jokes are the most popular and frequent jokes that home in on the social differences and rivalries between different groups, mostly used by the established majority to display their social, economic, and political power or superiority to the minority ethnic groups (Boskin \& Dorinson 1985). Davies (1990), who has studied ethnic jokes more systematically in different societies, examined the human traits such as dumbness, aggression, and stinginess that these jokes attribute to different ethnic groups. He focused specifically on the theme of stupidity, originally posited by Hobbes (1981), in his interpretation of ethnic jokes and joke telling behavior. Davies (1990) noted that the so-called stupid characters of the ethnic jokes have always been the people that live in the periphery, such as immigrants from the less developed parts of a country and those who more often than not speak a non-standard language. Ethnic joke wars in multicultural industrial societies during the 1940s and 1950s were also targeting unskilled immigrants, splitting people into two acceptable and unacceptable camps based on their ethnicity, to the extent that the court in America intervened to punish the offenders (Hughes 2003).

Political jokes, as another category of jokes, reveal the citizens' attitudes and struggle to resist the exerted pressure by a state to "standardize their thinking and to frighten them into withholding criticism and dissent" (Benton 1988: 33). Such jokes, which generally arouse a thought-provoking laughter, poke fun at the incompetent politicians and their policies. Political jokes fall into two main groups: those that denigrate political figures by representing them as stupid, tyrant, and unpopular; and exposure jokes that inform the public of the politicians' corruption or their abuse of power. Political jokes are hostile in nature and are exchanged in protest against the status quo (Kulynych 1997; Hart 2007). Text messages exchanged from Tahrir Square in Egypt before Mubarak's departure, saying, for instance, "Talk to him in Hebrew, he might understand", are the most recent examples of jokes serving the agenda of political protest. 
Jokes have also been found to offer the joke tellers and hearers mental and psychological benefits, or otherwise represent their mental or psychological states (Ruch 1998; Martin 2007). Jokes could be "inherently neither friendly nor aggressive", but serve as "a means of deriving emotional pleasure that can be used for both amiable and antagonistic purposes" (Martin 2007: 18). In his attempt to ascertain the unconscious and unseen forces behind them, Freud (1960 [1905]) classified them into innocent - those without a serious aim - and tendentious or purposeful jokes, which are laden with a serious message. He suggested that jokes allow for a release of hostile impulses that society will not tolerate; the feelings that are repressed by ego and superego mechanisms; and the voices that are censored by moral conscience. For example, Freud (ibid.) categorized political humor under hostile jokes, although this seems to be determined more contextually and culturally than demonstrating a universal truth. As another example, he located sexual jokes in a situation in which a woman initially arouses a male's sexual desire and then frustrates it.

The relationship between gender and humor has been another source of debate to examine the ways men and women engage in constructing gender identity (see Holmes 2006). In general, it has been observed that the patterns of humorous attacks are ingrained in many societies, and they are practiced as ritual duels much more by men than women (Kotthoff 2006). In addition, since it is unacceptable to assault or show aggression towards women directly, some people find it more appropriate to convey these hostile feelings through joking. Men have traditionally marginalized, restricted, or ignored women while participating in humorous practices to the extent that they have constructed stereotypes such as the very joke that women do not understand jokes (Bullough \& Bullough 1994; Kotthoff 2006). Although their level of involvement and indulgence in humor varies from one context to another, women in developing countries such as Iran - despite the dramatic developments - have yet to fulfill their utmost potential in terms of narrowing the gap with men in all social undertakings, especially in making and exchanging of jokes.

In summary, individuals follow different agendas while telling jokes, and the reaction that these jokes generate may be either positive or negative. Whether jokes are preeminently cracked for fun or are indicative of some people's anger and frustration, "a violation of the dignity, comfort, etc., of a disliked character seems to be acceptable, gratifying, and positively pleasurable to humans" (Veatch 1998: 181). Apart from violating others' social rights in many cases, humor can have a strong voice in promoting solidarity and bringing people together for a cause. This was evident in the controversial case of publication of Prophet Mohammed's cartoon by a Danish newspaper, which caused anger among Islamic countries and united them to protest against the offenders 
(Kuipers 2008). Jokes in the workplace also proved to increase the sense of collegiality among the staff, besides turning the tedious working conditions into more tolerable situations (Holmes 2006). Similarly, jokes could release pressure and tension among people in society at large, and consequently enhance their intimacy (Cohen 2001 [1999]). This was even noticed among tribal families who exchanged jokes as a means of entertainment and building emotional bonds with each other (Reddy 2003).

\section{THE STUDY}

This study intends to classify Persian jokes based on their targets, and to investigate their functions as to what different individuals may project, hide, or simply demonstrate while exchanging jokes. The researcher aims to offer insights into the destructive or constructive power of jokes in the ethnically and linguistically diverse Iranian society. Readers from other cultures can also get a glimpse into the ways Iranians exploit jokes for different personal or social purposes (Kazarian 2011). To achieve this aim, a corpus of 1000 Persian jokes was randomly collected from different online websites and classified into different categories based on their targets. In addition, a 14-item survey was designed in Persian and e-mailed to 200 male and female university students in different provinces in order to investigate their opinions on different features and functions of jokes. These items, which rated on a five-point Likert scale anchored at 1 ('strongly disagree') and 5 (strongly agree), fell into different inventories, such as general characteristics of Persian jokes, ethnic, political, and sexist jokes. University students were selected to ensure their familiarity with completing surveys. Students also form a segment of society that stands at the forefront of social and political changes, and therefore they are at a better vantage point to reflect on such social issues as joking practices. For the sake of easy reporting, the responses of 'strongly agree' and 'agree', as well as 'strongly disagree' and 'disagree', were combined together into 'agree' and 'disagree' categories. Representative jokes, which were translated from Persian into English by the researcher, were reported in support of the findings wherever deemed necessary. 


\section{RESULTS AND DISCUSSION}

The distribution of jokes according to their targets shows that ethnic jokes $(82.1 \%)$ accounted for an overwhelming majority of Persian jokes, followed by political (8.7\%), sexist (5.2\%), animal (2\%), and other types of jokes (2\%). In addition, the participants' responses to different items in the survey provided some insights into the function and role of these jokes. The sections below report the results of the data analysis and discussion of participants' responses to different parts of the survey.

\section{GENERAL CHARACTERISTICS OF PERSIAN JOKES}

Regarding their opinions on the specific features of Persian jokes, a majority of respondents (70\%) agreed that these jokes are exchanged for fun (item 1). This indicates that humor is basically a social phenomenon, and we laugh at jokes more frequently when mixing with others, although this pleasant feeling comes from making fun of others or demonstrating our own superiority to them (Martin 2007). An overwhelming majority of respondents (82\%) opined that Persian jokes are culture-specific (item 2), suggesting that funny jokes in one culture may be offensive or arouse no special reaction in another culture because different cultural groups enjoy different moral and social commitments and attachments (Veatch 1998). In order for the audience to appreciate a joke, they need to share some common socio-cultural and sociolinguistic understanding with the joke teller. Jokes are also time- and place-bound: those that attract the attention of one generation may not be of interest to another generation (ibid.). In spite of these differences, Persian jokes share some linguistic features with jokes from other cultures. For example, they vary in length, form, and content. They are also narrated in different modes such as declarative, imperative, and subjunctive, or different voices such as passive and active. Yet, most of these jokes are short narratives that begin with a description of the main character, followed by a funny story, as seen in the following joke:

Ghazanfar was dying. He told his son to let everybody know that his father died of HIV/AIDS.

"Why?" his son asked.

"It is a prestigious disease. Besides that, nobody will marry your mother," Ghazanfar answered. (http://www.4jok.com/show/jok/1391)

Participants (70\%) agreed that nothing is sacred when individuals engage in joking practices (item 3), as jokes are more likely than other humorous genres 
to violate the moral, ideological, or religious taboos. Davies (2005) has also observed that jokes made during socialist time in the Eastern Bloc showed no respect for the sacred values or institutions. However, while participants (76\%) agreed that everybody, regardless of their age or status, enjoys exchanging jokes (item 4), they (48\%) did not support the idea that younger generations are behind making and spreading of jokes (item 5). Indeed, people from all walks of life such as doctors, teachers, businessmen, taxi drivers, and even the president (see below) participate in this funny enterprise.

Concerning the psychological impacts of jokes on the joke tellers (item 6) and hearers (item 7), half of the participants agreed that jokes affect both parties, implying that jokes are not exchanged in vacuum; rather, individuals are under the influence of different drives and impulses while deciding what type of joke to tell, in what manner, and to whom. Psychologically, we address "a neighboring and similar people, whom we can perceive as a comic imitation of ourselves, just as we might visit a hall of mirrors to laugh at our own distorted reflections" (Davies 1998: 29). In other words, jokes could stand as psychological projections of our negative traits such as craftiness, cowardliness, and greed we attribute to others who are different from us culturally, socially, or linguistically. These jokes seem to have a cathartic effect on joke tellers and their audience to feel better after releasing their negative or hostile feelings towards socially different others (Freud 1960 [1905]). This applies specifically to the Iranian context, in which media censorship and the Internet filtering by the state is so rife that people do not have the luxury of expressing their feelings and thoughts publicly. Whenever given a chance, people criticize the state policies through humorous practices or works of art. For example, 'Poetry Nights', which are supported by communities or university students, are the occasions when poets have the opportunity to violate taboos in the name of poetry. Most of these poems read during these gatherings are disguised jokes that ridicule the lack of political and social freedom in the country.

\section{ETHNIC JOKES}

Participants (72\%) agreed that ethnic groups are the main targets of Persian jokes (item 8). As jokes are told for an intended audience, they have an intended target as well. However, being the target of others' laughter is a painful experience most people seek to avoid due to its negative social consequences (Martin 2007). This target, which is usually chosen based on some different geographical, cultural, social, or linguistic aspects (Asgharzadeh 2007), does not refer to a small town, but simply symbolizes a larger region or a deeper ethnic 
division. For example, "jokes about people from the northwestern provincial town of Rasht refer to a linguistic minority who live on the borders between Iran on the one hand and Turkey and Azerbaijan on the other" (Davies 1998: 16). Ethnic jokes are produced and spread for different purposes and reasons. Most important, they are exploited to coerce the powerless minorities into conforming to the desired norms, ideals, and manners of the majority, who are not associated with any ethnic group, speak the standard language, and have more social and economic leverage. This power game may put joking under the category of more aggressive practices such as teasing, ridiculing, and sarcasm. For example, the following joke mocks some ethnic groups who are still strict or cautious about pre-marriage relations between young boys and girls:

At his wedding night, Cheraghali turns to his wife and asks, "Does your family know you are here?” (http://eima.ir/view/post:1659878)

The rise of the middle class and, as a result, the class conflict, is another reason for the spread of ethnic jokes. Most of the Iranian ethnic minorities were living in small communities and villages farming and raising livestock, but the breakdown of feudalistic system and also environmental issues such as consecutive droughts and the inefficiency of the government to support these communities facilitated their exodus to more densely inhabited areas for better living standards and job opportunities. In order to survive the costly and difficult urban life, these immigrants had to compete with others, mostly with those who owned the means of production and business. Having conformed to the bourgeois ideals of the society through working hard, these newcomers managed to narrow the economic and social gap with the established majority. This sense of social and economic rivalry provoked the majority to make jokes at the expense of these minority groups in order to keep them at bay or to project their inabilities onto them, as the following joke shows:

"Have you ever experienced a miracle?" a TV reporter asked Ghazanfar. "Yes," Ghazanfar replied, "The other day I went to the bank, and when I got there ... Thank God ... the door opened automatically.” (http://andishgar. ir/view/post:352170)

Likewise, the joke below mocks another ethnic group's participation in sports activities, as if they should stay away from the activities that are considered to be within the realm of the dominant majority of the society:

As a football coach, Cheraghali realizes that number 10 player is not playing well. He calls him out and sends onto the pitch two number $5 \mathrm{~s}$ instead.

(http://forum.mobilestan.net/archive/index.php/t-92796.html) 
The rivalry argument is supported by the fact that Armenians living in the central provinces, Arabs living in the south, Baluchis living in the east, or even Afghan immigrants who are scattered across the country, are rarely the potential targets of jokes because they are demographically, geographically, or socially far from challenging the mainstream cultural or social status of the majority. Besides, there is no sectarian joke among Persian jokes because Shia is the official state religion, and Shiites comprise the majority religious group (more than 90\%); thus, they feel no potential threat from the small minority sects or religious groups.

As for the main theme of ethnic jokes, participants (66\%) agreed that ethnic jokes are loaded with the theme of stupidity (item 9 ). Joke tellers not only exert power on their audience and control their behavior but also impose their inner thoughts and mentalities on them (Martin 2007). This mainly includes the joke tellers' attempt to show their smartness at the expense of others' stupidity. However, these bitter ethnic jokes with negative themes could diminish the ethnic groups' tolerance for this type of contemptuous behavior and therefore provoke them to protest against the offenders in different ways. A couple of years ago, an ethnic group made an upheaval, protesting that the former President of the country (between 1997 and 2005) poked a joke at them in a private meeting with some clerics, although he later called it a political smear campaign. In order to regain their lost ground and social dignity, many ethnic groups have recently managed to fire back by making and spreading jokes on different blogs at the expense of Persian speakers.

While previous research gives evidence of true stories behind ethnic jokes (Davies 1990; Chiaro 1992), Persian jokes demonstrate this veracity in terms of cultural, linguistic, and socio-economic disparities rather than in terms of the ethnic groups' actual stupidity or ignorance. For example, some of these jokes target ethnic groups who are not competent bilinguals, or incapable of communicating in standard language as efficiently as native speakers. By the same token, participants (64\%) agreed that ethnic jokes are narrated in the targeted ethnic group's dialect or language (item 10). These jokes address these groups' use of syntactically or phonologically marked Persian due to the existence of different structures or phonemes in their mother tongue. For example, jokes about Azeri speakers target their inability to articulate the consonants such as /k/, /g/, and /gh/ properly while speaking Persian. Because of their insufficient exposure to the standard language, these jokes also target their deviant use of the pragmatic and discourse conventions of this language. Therefore, the hegemony of Persian as the standard language not only has marginalized minority languages and vernaculars but also has turned their speakers into a target of jokes. 
Another challenge to this veracity debate derives from the fact that the same ethnic jokes are attributed to different funny characters representing different ethnic groups. For example, if the joke is neutral, it will have yaroo (a guy) as its main character; however, if joke tellers realize that the context is conceivable to apply it to an ethnic group, they will change the character's name to fit that ethnic group. This repetitive application of the same joke to different ethnic groups justifies the claim that most ethnic jokes are somehow blind rather than depicting a true story. For example, the following joke was narrated with two different funny characters that represent two different ethnic groups:

During the war between Iran and Iraq, Ghazanfar sends a message to his comrades saying that he has captured 4 Iraqi soldiers and needs their help to collect the captive.

"Bring them yourself. Will you?" they reply.

"I am afraid I can't. They don't let me move," he replies back.

(http://www.ninisite.com/discussion/thread.asp?threadID=561303\&Pa geNumber $=1$ )

This common strategy also applies to the geographical locations of different ethnic groups. As an example, the joke below was narrated in two distant provinces, where two different ethnic groups live:

An earthquake killed 89 people in Lorestan: 9 people were killed as they were trapped under the rubble, and another 80 died as the result of fighting over the relief goods such as tents and blankets. (http://faceloos.ir/view/ post:323130)

\section{POLITICAL JOKES}

Concerning their opinions on the functions of political jokes, participants (62\%) agreed that these types of jokes protest against the lack of freedom of speech and expression in society (item 11). In addition, they (52\%) agreed that these jokes carry a political agenda (item 12). In most cases, political jokes reflect the people's disapproval of the politicians' decisions in response to the high-stake issues (Kulynych 1997; Hart 2007). For example, people have recently spread jokes to react against the state strategy of 'economy of resistance', which was developed to curb the impact of international sanctions on the country. It could therefore be highly unlikely to believe that someone supports a political system and ridicules or censures it with humorous practices such as joking. Since the government has closed down the daily newspapers that oppose the dominant 
fundamentalists, filtered the online social networking sites such as Facebook, YouTube, and Twitter, which people might use to share their opinions and information freely, and has prosecuted its critics for the past three decades, people have been exploiting jokes as an outlet to express their criticism. Other types of humor practices are also subjected to this crackdown. As a recent example, a cartoonist has been sentenced to 25 lashes for drawing a cartoon of a member of parliament, suggesting the state's zero tolerance towards using humor even against low-ranking officials. These policies have provoked people to defy this social suppression through employing humor, as echoed best in the following joke:

Ahmadinejad: In my dream I saw 8 Mongolians bring me some plum soup. Joseph's interpretation: You will destroy the country to the point that people send blessings upon Genghis Khan of Mongolia. (http://jock-18. glxweb.ir/post/5/profile.php)

Likewise, the joke below illustrates people's concern about the incapacity of the government to strike a deal with the countries involved over its nuclear program in the past 12 years.

Finally the President sent the Group 5+1 a letter responding to their proposal for the nuclear talks.

“The answer is 6," he wrote back to them. (http://www.lakke33.blogfa. com/8706.aspx)

Although these jokes function as a source of solidarity among people outside the circle of power, more often than not they reveal the hypocrisy, conformity, and conservatism of those who spread jokes to perpetuate a culture of sneering and smirking at serious issues instead of expressing their legitimate demands through other outlets. This popular joking culture has dared politicians themselves to exploit jokes in order to move their agenda ahead or to belittle the opposition (Paletz 1990). During his presidential campaign, Ahmadinejad, the sixth President of Iran (2005-2013), promised people to put their share of exported oil revenue on their dinner table, so to speak. After taking the office, however, he did not keep to his promise and instead joked that the tablecloth would get oily if he proceeded with the plan. Ethnic jokes could even follow a political agenda in this context. They could leave an escapist impact on the poor by diverging their attention from their daily life problems and also entertain and titillate the middle class and affluent to feel happy and forget about the rest. Moreover, cracking down on the political jokes and disseminating ethnic jokes could, in the long term, create politically inactive or indifferent individuals, who, for the fear of 'big brother', go down the trodden path of having fun at the expense of their fellow citizens. 


\section{SEXIST JOKES}

As for the relationship between joking and gender, participants (48\%) disagreed that joking is a male-dominant practice (item 13). Thanks to the global women's rights movements and initiatives, women in Iran have also attained rights equal to men in many respects, although there is still a long way to go before they can achieve equal footing with men in all segments of family, social, and professional life. For example, girls have outnumbered boys in many disciplines in higher education, especially in social sciences studies, and they are enthusiastically participating in the humor duel, as is seen in the following joke:

Men are like parking spaces. All the good ones are taken and the rest are handicapped.

(http://jokbazar2000.mihanblog.com/post/51)

Finally, participants (66\%) disagreed that women are the targets of Persian jokes (item 14). The analysis of the pile of jokes also illustrated that there were more jokes about men than women. This gives evidence of a conscious movement, in particular among the educated women, to be aware of the power of humor in proving their equality and capability in the society, as the following joke has it:

A: What do you call a man who's lost $99 \%$ of his mind?

B: Infertile. (http://www.jokekhoone.com)

\section{CONCLUSIONS}

The results from this study indicate that the main targets of Persian jokes are ethnic groups, especially those who challenge the hegemony of the mainstream majority by living or working with them neck and neck. This highlights the significance of ethnicity, which is mainly marked by a different language or a geographical location, as a strong indicator of social identity in today's Iranian society. These jokes depict ethnic groups as stupid and ignorant because of their different cultural and social norms and values. The popularity of ethnic jokes proves the principle that people make jokes at the expense of others, ignoring a basic fact that "most people are personally offended when they are laughed at" (Veatch 1998: 176). Not only could these jokes whip up ethnocentric sentiments and tensions among different ethnic groups, but they could also damage people's respect for the ethnic diversity and peaceful co-existence in society.

Political jokes also make up a fraction of Persian jokes, emanating from people's soft social protest and criticism voiced against the lack of freedom in 
a theocratic system of statehood (Benton 1988: 33). They reveal people's reaction to the widespread social and political crackdown that has left room only for spiteful jokes or sneering and smirking at the politicians they dislike the most (Veatch 1998). However, the small proportion of sexist jokes reveals that more crucial aspects of identity politics such as ethnicity, alongside political concerns, have overshadowed the gender issue, albeit there are still religious and moral taboos associated with making jokes about women. Moreover, Iranian women have avoided being the target of jokes by narrowing the gap with men in different areas of professional and social life. Consulting the pile of jokes, sexist jokes were the least likely local types of jokes, highlighting a global taste among women to align themselves with more international women's rights movements against the likely unequal opportunities in various aspects of their life.

This study concludes that jokes not only mirror the realities of society but also help perpetuate those negative mentalities and stereotypes. The popularity of joking practices could give an account of the collective disappointment of people who embark on making and exchanging of jokes to vent their social and political frustration. This is best reflected in the prevalence of ethnic jokes, by which people are intentionally or unintentionally engaged in the ethnic identity politics. However, there is also a conspiracy theory that the state welcomes ethnic jokes in order to keep people distracted from the main political or economic issues. This is reflected in their concern over political rather than ethnic jokes by censoring and filtering the media or online sources that contain such materials. Launching a special cyber police force to deal with the cyber crimes, humor practices included, is another example of the state's iron-fist policy towards violators of the so-called revolutionary and ideological principles.

Although the findings of this study are not conclusive because of the small pile of jokes and the size of the sample, they can provide a snapshot of the taxonomy, as well as different social, political, and psychological functions and implications of Persian jokes. Since investigating jokes falls within the domain of interdisciplinary research, further study needs to employ more qualitative means of data collection with more participants from different walks of life and ethnic groups in order to draw a better picture of jokes and their functions in the contemporary Iranian society. 


\section{REFERENCES}

Asgharzadeh, Alireza 2007. Iran and the Challenge of Diversity: Islamic Fundamentalism, Aryanist Racism, and Democratic Struggles. New York \& Basingstoke: Palgrave Macmillan.

Attardo, Salvatore 1994. Linguistic Theories of Humor. Berlin \& New York: Mouton de Gruyter.

Benton, Gregor 1988. The Origins of the Political Joke. In: Chris Powell \& Georg E.C. Paton (eds.) Humour in Society: Resistance and Control. New York: St. Martin's Press, pp. 33-55.

Bergson, Henri 2004 [1911]. Laughter: An Essay on the Meaning of the Comic. Montana: Kessinger Publishing.

Boskin, Joseph \& Dorinson, Joseph 1985. Ethnic Humor: Subversion and Survival. American Quarterly, Vol. 37, No. 1, pp. 81-97.

Bullough, Vern L. \& Bonnie, Bullough (eds.) 1994. Human Sexuality: An Encyclopedia. London: Taylor \& Francis.

Chiaro, Delia 1992. The Language of Jokes: Analysing Verbal Play. London: Routledge.

Cohen, Ted 2001 [1999]. Jokes: Philosophical Thoughts on Joking Matters. Chicago \& London: University of Chicago Press.

Davies, Christie 1990. Ethnic Humor around the World: A Comparative Analysis. Bloomington: Indiana University Press.

Davies, Christie 1998. Jokes and Their Relation to Society. Berlin: Mouton de Gruyter.

Davies, Christie 2005. Jokes and Groups. London: The Institute for Cultural Research.

Davies, Christie 2007. Humour and Protest: Jokes under Communism. International Review of Social History, Vol. 52, No. 15, pp. 291-305. http://dx.doi.org/10.1017/ S0020859007003252.

Freud, Sigmund 1960 [1905]. Jokes and Their Relation to the Unconscious. Transl. by James Strachey. London: Penguin.

Hart, Marjolein 't 2007. Humour and Social Protest: An Introduction. International Review of Social History, Vol. 52, No. 15, pp. 1-20. http://dx.doi.org/10.1017/ S0020859007003094.

Hobbes, Thomas 1981. Leviathan. London: Penguin Books.

Holmes, Janet 2006. Sharing a Laugh: Pragmatic Aspects of Humor and Gender in the Workplace. Journal of Pragmatics, Vol. 38, No. 1, pp. 26-50. doi:10.1016/j. pragma.2005.06.007.

Holt, Jim 2008. Stop Me If You've Heard This: A History and Philosophy of Jokes. New York \& London: W. W. Norton.

Hughes, Melissa K. 2003. Through the Looking Glass: Racial Jokes, Social Context, and the Reasonable Person in Hostile Work Environment Analysis. Southern California Law Review, Vol. 76, No. 6, pp. 1437-1482. Available at http:// lawreview.usc.edu/wp-content/uploads/slideshow/Hughes_Melissa_76_6.pdf, last accessed on November 28, 2014.

Kazarian, Shahe S. 2011. Humor in the Collectivist Arab Middle East: The Case of Lebanon. Humor: International Journal of Humor Research, Vol. 24, No. 3, pp. 329-348. http://dx.doi.org/10.1515/humr.2011.020. 
Kotthoff, Helga 2006. Gender and Humor: The State of the Art. Journal of Pragmatics, Vol. 38, No. 1, pp. 4-25.

Kuipers, Giselinde 2008. The Muhammed Cartoon Controversy and the Globalization of Humor. Humor: International Journal of Humor Research, Vol. 21, No. 1, pp. 7-11.

Kulynych, Jessica 1997. Performing Politics: Foucault, Habermas, and Postmodern Participation. Polity, Vol. 30, No. 2, pp. 315-346. http://dx.doi.org/10.2307/3235221.

LaFollette, Hugh \& Shanks, Niall 1993. Belief and the Basis of Humor. American Philosophical Quarterly, Vol. 30, pp. 329-339. Available at http://www.hughlafollette. com/papers/humor.htm, last accessed on November 28, 2014.

Martin, Rod A. 2007. The Psychology of Humor: An Integrative Approach. London: Elsevier Academic Press.

Oshima, Kimie 2000. Ethnic Jokes and Social Function in Hawai'i. Humor: International Journal of Humor Research, Vol. 13, No. 1, pp. 41-58. http://dx.doi.org/10.1515/ humr.2000.13.1.41.

Paletz, David L. 1990. Political Humor and Authority: From Support to Subversion. International Political Science Review / Revue internationale de science politique, Vol. 11, No. 4, pp. 483-493. http://dx.doi.org/10.1177/019251219001100406.

Pérez-Arce, Patricia 1999. The influence of culture on cognition. Archives of Clinical Neuropsychology, Vol. 14, No. 7, pp. 581-592. http://dx.doi.org/10.1016/S08876177(99)00007-4.

Provine, Robert R. 2000. Laughter: A Scientific Investigation. New York: Viking.

Raskin, Victor 1985 [1944]. Semantic Mechanisms of Humor. Dordrecht \& Boston \& Lancaster: D. Reidel Publishing Company.

Reddy, Viswanadha K. 2003. A Study of Socio-Linguistic Aspects of Kin Behavior among the Yerukala Tribe in Rayalaseema Region of Andhra Pradesh. Anthropologist, Vol. 5, No. 2, pp. 107-112. Available at http://www.krepublishers.com/02-Journals/ T-Anth/Anth-05-0-000-000-2003-Web/Anth-05-2-067-140-2003-Abst-PDF/Anth05-2-107-112-2003-Reddy-K-V/Anth-05-2-107-112-2003-Reddy-K-V-Text.pdf, last accessed on November 28, 2014.

Ruch, Willibald 1998. The Sense of Humor: Exploration of a Personality Characteristic. Berlin: Mouton de Gruyter.

Taraghi, Hamidreza 2012. Jokes Unfairly Made about Ayatollah Jannati Will Make Him More Determined in His Way. Khabar Online, October 12. http://www. khabaronline.ir, last accessed on November 28, 2014.

Veatch, Thomas C. 1998. A Theory of Humor. Humor: International Journal of Humor Research, Vol. 11, No. 2, pp. 161-216. http://dx.doi.org/10.1515/humr.1998.11.2.161. 